1 Department of Biology, Emory University, Atlanta GA, USA

2 Department of Biology, Center for Infectious Disease Dynamics, Pennsylvania State University, University Park, PA, USA

Correspondence to: J S Lavine jslavin@emory.edu

Cite this as: BMJ 2021;373:n1197 http://dx.doi.org/10.1136/bmj.n1197 Published: 13 May 2021

\section{Vaccinating children against SARS-CoV-2}

\author{
Hard to justify right now for most children in most countries \\ Jennie S Lavine, ${ }^{1}$ Ottar Bjornstad, ${ }^{2}$ Rustom Antia'
}

Following widespread vaccination against SARS-CoV-2 of older adults and other highly vulnerable groups, some high income countries are now considering vaccinating children; just days ago, the US Food and Drug Administration authorized the use of the Pfizer/BioNTech vaccine in children 12-15 years of age. Young people have been largely spared from severe covid-19 so far, ${ }^{12}$ and the value of childhood vaccination against respiratory viruses in general remains an open question for three reasons: the limited benefits of protection in age groups that experience only mild disease ${ }^{3}$; the limited effects on transmission because of the range of antigenic types and waning vaccine induced immunity ${ }^{4}$; and the possibility of unintended consequences related to differences in vaccine induced and infection induced immunity. ${ }^{5}$ We discuss each in turn.

\section{Protection}

The cost-benefit balance of any vaccination campaign depends on disease burden in the target population and available resources. ${ }^{6}$ Covid-19 severity in children under the age of 12 is similar to that of influenza, ${ }^{7}$ and as health resources are stretched thin even in high income countries vaccinating children is unlikely to be a priority. Preliminary data suggest that disease caused by variants of concern remains mild in young children, ${ }^{8-10}$ although close monitoring of newly emerging variants remains essential. Were one to emerge that caused severe disease in children (like Middle East respiratory syndrome), vaccinating children would become a priority.

Additionally, vaccination may be particularly valuable for some subgroups. Certain chronic conditions, including obesity, predispose children to more severe covid-19, ${ }^{11}$ and those with markers of inflammation and cardiac distress, such as high levels of $C$ reactive protein, interleukin -6 , and brain natriuretic peptide, are more likely to develop serious sequelae such as multisystem inflammatory syndrome. ${ }^{12}$ Studies to identify whether laboratory markers before infection can predict risk of multisystem inflammatory syndrome should be a research priority, to help target vaccination to vulnerable children.

\section{Transmission}

Recent studies provide evidence that mass vaccination reduces population transmission of SARS-CoV-2. ${ }^{13}$ School age children and teenagers generally have higher rates of social contact than older adults, ${ }^{14}$ so vaccinating children might reduce circulation of pathogen and protect older and more vulnerable adults from exposure. ${ }^{15}$ However, children seem to be less susceptible than adults to both infection and transmission of SARS-CoV-2, ${ }^{16}{ }^{17}$ and countries such as Norway maintained low transmission rates despite keeping primary schools open. Both suggest a limited role for young children in sustaining chains of transmission ${ }^{18}$ and that vaccinating children is likely to be of marginal benefit in reducing the risk to others.

New variants are emerging as the virus adapts to its human host and to the immunity generated by previous SARS-CoV-2 infections and vaccination. It is therefore essential to continue monitoring disease severity across all age groups so vaccination strategies can be adapted rapidly if required. For example, adults seem to retain substantial immunity for at least eight months after vaccination or natural infection, ${ }^{19-21}$ but if ageing immune systems and waning immunity against new variants lead to shorter protection from severe disease, updated vaccines for adults and vaccinating children to reduce transmission may become more desirable. Additionally, emergence of variants with increased severity in children, or in adults with previous immunity, would signal a more urgent need to control both transmission and disease through vaccinating children.

\section{Unintended consequences}

Unfortunately, as virus circulation decreases, the age of primary infection increases, and since age is directly associated with pathogenicity, vaccinating children would likely lead to lower infection rates but higher case fatality rates. ${ }^{22}$ Additionally, depending on the relative durations of immunity induced by vaccines and infection, and the rate of viral antigenic change, vaccinating children might increase the frequency of large seasonal epidemics, leading to overall increases in virus induced morbidity and mortality. ${ }^{5}$

Finally, mRNA vaccines against SARS-CoV-2 induce greater antibody responses than natural infection but may elicit CD8 $\mathrm{T}$ cell responses that are less broadly protective against future variants. ${ }^{2324}$ Further studies on the differences between vaccine and infection induced immunity should be done to explore and quantify these trade-offs.

\section{Balanced decision}

Should childhood infection (and re-exposures in adults) continue to be typically mild, childhood vaccination will not be necessary to halt the pandemic. The marginal benefits should therefore be considered in the context of local healthcare resources, equitable distribution of vaccines globally, and a more nuanced understanding of the differences between vaccine and infection induced immunity. 
Once most adults are vaccinated, circulation of SARS-CoV-2 may in fact be desirable, as it is likely to lead to primary infection early in life when disease is mild, followed by booster re-exposures throughout adulthood as transmission blocking immunity wanes but disease blocking immunity remains high. ${ }^{22} 25$ This would keep reinfections mild and immunity up to date.

Monitoring disease severity remains critical, however, in both immunologically naive children and vaccinated or previously infected adults, so we can adapt our control strategies as the virus adapts to us.

Competing interests: The BM/ has judged that there are no disqualifying financial ties to commercial companies. The author declares no other interests. Further details of The BM/policy on financial interests is here: https://www.bmj.com/sites/default/files/attachments/resources/2016/03/16-current-bmj-education-coi-form.pdf.

Provenance and peer review: Commissioned; not externally peer reviewed.

1 Dong Y, Mo X, Hu Y, etal. Epidemiology of COVID-19 among children in China. Pediatrics 2020;145:e20200702. doi: 10.1542/peds.2020-0702 pmid: 32179660

2 Tregoning JS, Schwarze J. Respiratory viral infections in infants: causes, clinical symptoms, virology, and immunology. Clin Microbiol Rev 2010;23:74-98.

doi: 10.1128/CMR.00032-09 pmid: 20065326

3 Prosser LA, Bridges CB, Uyeki TM, etal. Health benefits, risks, and cost-effectiveness of influenza vaccination of children. Emerg Infect Dis 2006;12:1548-58

doi: 10.3201/eid1210.051015 pmid: 17176570

4 Belongia EA, Sundaram ME, McClure DL, Meece JK, Ferdinands J, VanWormer JJ. Waning vaccine protection against influenza A (H3N2) illness in children and older adults during a single season. Vaccine 2015;33:246-51. doi: 10.1016/j.vaccine.2014.06.052 pmid: 24962752

5 de Boer PT, Backer JA, van Hoek AJ, Wallinga J. Vaccinating children against influenza: overall cost-effective with potential for undesirable outcomes. BMC Med 2020;18:11. doi: 10.1186/s12916-019-1471-x pmid: 31931789

6 World Health Organization. Vaccines against influenza WHO position paper-November 2012 Wkly Epidemiol Rec 2012;87:461-76.pmid: 23210147

7 Piroth L, Cottenet J, Mariet AS, etal. Comparison of the characteristics, morbidity, and mortality of COVID-19 and seasonal influenza: a nationwide, population-based retrospective cohort study. Lancet Respir Med 2021;9:251-9. doi: 10.1016/S2213-2600(20)30527-0 pmid: 33341155

8 Santos de Oliveira M, Lippi G,, Henry B. Sudden rise in COVID-19 case fatality among young and middle-aged adults in the south of Brazil after identification of the novel B.1.1.28.1 (P.1) SARS-CoV-2 strain: analysis of data from the state of Parana.medRxiv 2021.03.24.21254046. [Preprint.] doi: 10.1101/2021.03.24.21254046.

9 Bhopal SS, Bagaria J, Olabi B, Bhopal R. Children and young people remain at low risk of COVID-19 mortality. Lancet Child Adolesc Health 2021;5:e12-3. doi: 10.1016/S2352-4642(21)00066-3 pmid: 33713603

10 Davies NG, Jarvis Cl, Edmunds WJ, Jewell NP, Diaz-Ordaz K, Keogh RHCMMID COVID-19 Working Group. Increased mortality in community-tested cases of SARS-CoV-2 lineage B.1.1.7. Nature 2021. doi: 10.1038/s41586-021-03426-1 pmid: 33723411

11 Fernandes DM, Oliveira CR, Guerguis S, etalTri-State Pediatric COVID-19 Research Consortium. Severe acute respiratory syndrome coronavirus 2 clinical syndromes and predictors of disease severity in hospitalized children and youth. J Pediatr 2021:230:23-31.e10. doi: 10.1016/j.jpeds.2020.11.016 pmid: 33197493

12 Abrams JY, Oster ME, Godfred-Cato SE, etal. Factors linked to severe outcomes in multisystem inflammatory syndrome in children (MIS-C) in the USA: a retrospective surveillance study. Lancet Child Adolesc Health 2021;5:323-31. doi: 10.1016/S2352-4642(21)00050-X pmid: 33711293

13 Milman O, Yelin I, Aharony N, etal. SARS-CoV-2 infection risk among unvaccinated is negatively associated with community-level vaccination rates.medRxiv 2021.03.26.21254394. [Preprint.] doi: 10.1101/2021.03.26.21254394.

14 Mossong J, Hens N, Jit M, etal. Social contacts and mixing patterns relevant to the spread of infectious diseases. PLoS Med 2008;5:e74. doi: 10.1371/journal.pmed.0050074 pmid: 18366252

15 Hilton J, Keeling MJ. Incorporating household structure and demography into models of endemic disease. J R Soc Interface 2019;16:20190317. doi: 10.1098/rsif.2019.0317 pmid: 31387486

16 Ismail SA, Saliba V, Lopez Bernal J, Ramsay ME, Ladhani SN. SARS-CoV-2 infection and transmission in educational settings: a prospective, cross-sectional analysis of infection clusters and outbreaks in England. Lancet Infect Dis 2021;21:344-53. doi: 10.1016/S1473-3099(20)30882-3 pmid: 33306981

17 Zhang J, Litvinova M, Liang Y, etal. Changes in contact patterns shape the dynamics of the COVID-19 outbreak in China. Science 2020;368:1481-6. doi: 10.1126/science.abb8001 pmid: 32350060

18 Brandal LT, Ofitserova TS, Meijerink H, etal. Minimal transmission of SARS-CoV-2 from paediatric COVID-19 cases in primary schools, Norway, August to November 2020. Euro Surveill 2021;26:26. doi: 10.2807/1560-7917.ES.2020.26.1.2002011 pmid: 33413743
19 Tarke A, Sidney J, Methot N, etal. Negligible impact of SARS-CoV-2 variants on CD4+ and CD8+ T-cell reactivity in COVID-19 exposed donors and vaccines.bioRxiv2021.02.27.433180. [Preprint]. doi: 10.1101/2021.02.27.433180

20 Dan JM, Mateus J, Kato Y, etal. Immunological memory to SARS-CoV-2 assessed for up to 8 months after infection. Science 2021;371:371. doi: 10.1126/science.abf4063 pmid: 33408181

21 Hitchings MDT, Ranzani OT, Scaramuzzini Torres MS, etal. Effectiveness of CoronaVac in the setting of high SARS-CoV-2 P.1 variant transmission in Brazil: A test-negative case-control study.medRxiv 2021.04.07.21255081. [Preprint.] doi: 10.1101/2021.04.07.21255081

22 Coleman PG, Perry BD, Woolhouse ME. Endemic stability--a veterinary idea applied to human public health. Lancet 2001;357:1284-6. doi: 10.1016/S0140-6736(00)04410-X pmid: 11418173

23 Tarke A, Sidney J, Kidd CK, etal. Comprehensive analysis of T cell immunodominance and immunoprevalence of SARS-CoV-2 epitopes in COVID-19 cases. Cell Rep Med 2021;2:100204. doi: 10.1016/j.xcrm.2021.100204 pmid: 33521695

24 Ivanova EN, Devlin JC, Buus TB, etal. Discrete immune response signature to SARS-CoV-2 mRNA vaccination versus infection.medRxiv 2021.04.20.21255677. [Preprint.]pmid: 33907755

25 Edridge AWD, Kaczorowska J, Hoste ACR, etal. Seasonal coronavirus protective immunity is short-lasting. Nat Med 2020;26:1691-3. doi: 10.1038/s41591-020-1083-1 pmid: 32929268

This article is made freely available for use in accordance with BMJ's website terms and conditions for the duration of the covid-19 pandemic or until otherwise determined by BMJ. You may use, download and print the article for any lawful, non-commercial purpose (including text and data mining) provided that all copyright notices and trade marks are retained. 